\title{
Relationship of cow behavioral performance with milk productivity in the conditions of robotic milking
}

\author{
Lenar R. Zagidullin ${ }^{1, *}$, Rifat R. Khisamov ${ }^{1}$, Rubin R. Kayumov ${ }^{1}$ and Radik R. Shaidullin ${ }^{2}$ \\ ${ }^{1}$ Kazan State Academy of Veterinary Medicine named after N.E. Bauman, Kazan 420029, Russia \\ ${ }^{2}$ Kazan State Agrarian University, Kazan 420015, Russia
}

\begin{abstract}
Research has been conducted to study the cow's behavioral acts of the Tatarstan type of Kholmogory breed and their relationship with milk productivity in the robotic milking system. It was found that cows spend 706.7 minutes, or $49.1 \%$ of the daily time, in the lying position, and 733.3 minutes, or $50.1 \%$, in the standing position. Animals spend 283.7 minutes $(19.7 \%$ of the daily time) on taking food, 497.3 minutes $(34.5 \%)$ on rumination, of which 150 minutes $(10.4 \%)$ - standing, 347.3 (24.1) - lying down. 232.3 minutes $(16.1 \%)$ of the time the cows stood in one place and were inactive. The movement took 42.7 minutes or $3 \%$ of the daily time. After dividing the cows into 3 groups by productivity was found that highly productive animals were milked 1.9 times more compared to low-productivity animals (4.7 versus 2.7 times). They also spent more time standing (34.5\%), consumed more food (21.0\%), and chewed less cud $(13.9 \%)$. Animals assigned to the active and ultra-active groups by the motor activity index outperformed animals of the infro-passive and passive groups by $26.9 \%$ in daily milking.
\end{abstract}

\section{Introduction}

The scientific approach to the animal behavior study originates from the works of naturalists of the 18th century, such as G. White and Sh. Zh. Leroy, however, Charles Darwin is considered the founder of a scientific approach to the study of animal behavior [1]. Ethology took shape in the 30 s of the XX century. Its recognized founders are the Austrian zoologist K. Lorenz and the Dutch zoologist N. Tinbergen. They defined ethology as "the objective study of instinctive movements" (N. Tinbergen) or as "the morphology of animal behavior" (K. Lorenz). The researches of the Nobel-prize winner, academic I. P. Pavlov have of great importance. In 1903, using the method of behavior reflexes, he identified the main regularities of a conditioned-reflex activity and created the doctrine of higher nervous activity (behavior) $[2,3]$. The progress of this science is due to the need for ethology knowledge for idea forming of biological systems, for practical animal husbandry, effective organization of maintenance, breeding, and increasing productivity [4].

Along with the traditional system of step selection established in zootechnical practice by origin, exterior, body, productivity, and quality of offspring, it is important to forecast the productivity of animals taking into account their ethological features, which can be successfully used in stock breeding [5]. Livestock behavior is determined by both endogenous (hormonal, biochemical, and nervous) and exogenous factors, including technological factors [6]. The study of behavioral responses of animals of different breeds makes it possible to find ways to increase their productivity in specific conditions of feeding and keeping [7].

Ethological studies in dairy cattle breeding are relevant for the reason that the behavioral reactions of animals to a certain extent are determined by the genotype. The possibility of transmitting behavior features from parents to descendants has been known for a long time since when breeding live-stock animals and domestic animals, people not only saw the uniqueness of their behavior but also learned to get the desired combinations of behavioral signs in new breeds [8]. The share of the influence of hereditary factors on the index of food activity of animals reaches a maximum of 0.46 , motor activity to 0.70 , and total activity to 0.82 . In combination with the traditionally accepted selection of animals based on the productivity of female ancestors, the selection effect taking into account ethological indices increases significantly. The milk yield difference is highly reliable up to $19.3-25.1 \%$ [9].

The robotic milking system provides for the yard housing of animals, in which the behavior repertoire will be determined by the size of the animal's living space, feeding and drinking conditions, the availability of resting places and their comfort, lighting, ventilation systems, etc. The system creates favorable conditions for the manifestation of behavioral responses, the implementation of which would be limited or impossible with traditional technologies.

In this regard, the aim of the work was to correlation study of behavioral acts with the milk productivity of

Corresponding author: mehksavm@mail.ru 
cows of the Tatarstan type of Kholmogory breed under the robotic milking system.

\section{Materials and methods}

The research was conducted in the PFE "Akhmetov" of the Sabine district of the Republic of Tatarstan. The research objects were 15 cows of the Tatarstan type of Kholmogory breed, which are on 2-3 months of lactation. The animals were kept in a group consisting of 90 cows. Animals with different daily milk yield were selected for the study group. Observation of the marked animals was carried out during the day by the chronometry method of elementary behavior acts according to the method of V.I. Velikzhanina (2000) [10]. To analyze the results, the indices of food, motor, and general activity (IFA, IMA, IGA) were calculated using the following formulas: 1440

IFA = time spent eating food and chewing cud /

IMA = time spent standing, moving, eating food and chewing cud standing, milking / 1440;

IGA = time spent standing, moving, eating food, chewing cud standing, and lying down, milking / 1440.

The animal's distribution into high -, medium- and low productivity groups were performed using the $\pm 0.5 \sigma$ method [11]. Low-productivity animals were assigned to group I, medium-productive animals to group II, and highly productive animals to group III. Information about productivity and milking parameters on robots was taken from the information management system of the herd "Lely T4C". Statistical data processing was carried out according to generally accepted methods using the MS Excel program.

The cubicle system has the possibility of a free approach to two Lely A4 milking robots. Cows were fed with a multi-component mixed ration 2 times a day (in $8^{00}$ and $13^{00}$ ) and mixed feed-concentrate at milking stations. The room temperature during the research was plus $2-4{ }^{\circ} \mathrm{C}$.

\section{The results of the study}

Cows are highly social animals. The cubicle system of keeping provides cows with relative freedom of movement and the ability to contact other critters. The robotic milking system allows you to further increase the degree of animals freedom. They are allowed to choose the times milked per day. Also, the use of milking robots is excluded from the human milking process. And any contact of an animal with a person on the farm should be considered as a stress factor for it.

Cows are in two positions: lying down or standing up. Most behavioral acts are performed by animals in a standing position. The lying position is less energyconsuming and serves for rest. It was found that the cows were in the lying position for $706.7(\mathrm{Cv}=25.3 \%)$ minutes or $49.1 \%$ of the daily time. Almost half of the time they lay down (347.3 minutes or $24.1 \%$ ), the cows chewed the cud, and the remaining $25 \%$ of the time they were inactive (Fig. 1). The animals lay slightly more on their left side $(55.3 \%)$ than on their right $(44.7 \%)$.

The cows were standing position for 733.3 minutes (50.1\% of the daily time). The animals spent most of their standing time $(19.7 \%)$ taking food. The variability of this behavioral act is the lowest compared to all others $-\mathrm{Cv}=19.8 \%$. Cows stood in one place for an average of 232.3 minutes $(16.1 \%)$. At this time, they mostly did not show activity-they rested. Sometimes, however, showed social behavior in the allogrooming form mutual licking between two critters. The chewing process occurs also in the standing position. This took the animals 150.0 minutes or $10.4 \%$ of the daily time. It should be noted that the time of chewing standing varies greatly $(\mathrm{Cv}=70.3 \%)$ if this process lasts 40 minutes for one cow, the other 350. In general, cows spend 497.3 minutes of remastication of cud $(34.5 \%$ of the daily time).

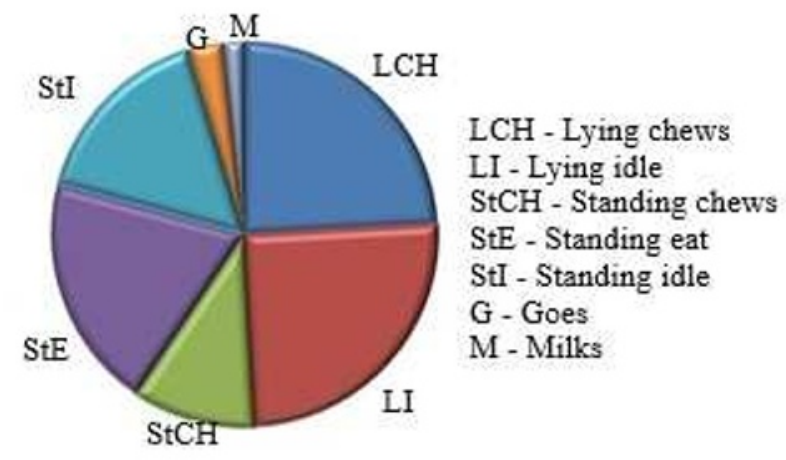

Fig. 1. The behavioral acts distribution for the day

Cows are not actively moving around the farm section. The average movement time is 42.7 minutes, or $3 \%$ of the daily time $(\mathrm{Cv}=51.6 \%)$. If the most passive cow moved for 10 minutes, the most active cow moved for 80 minutes. The cows spent 24.7 minutes in the milking box. If we consider that the average amount of milking was 3.8 times, the duration of the milking process was 6.5 minutes.

The cow behavior study in the conditions of industrial milk production technology is aimed not only at determining the essential behavior elements and their management, but also at determining the relationship of behavioral acts with economic characters. This knowledge will serve to further improve these features.

The average daily milk productivity of experimental cows was $21.0 \pm 1.45 \mathrm{~kg}$. After dividing them into 3 groups by productivity: in group I (low - productivity) there were 4 cows with a milk yield of $13.9 \mathrm{~kg}$, in group II (medium - productivity) there were 5 with a milk yield of $20.5 \mathrm{~kg}$, in group III (high-productivity) there were 6 with a milk yield of $26.3 \mathrm{~kg}$ (see Table 1).

There is a reliable relationship between milk productivity and the amount of milking. Group II cows were milked by 0.8 ( $p<0.05)$, group III by 1.9 times more $(p<0.01)$ than group I animals. Figure 2 shows the distribution curve of the amount of milking of cows per day. You can note a certain milking activity in the time interval between 8 and 12 hours, during which $30 \%$ of the daily number of milking occurred. On 4 milking for one hour is observed in the intervals between 15-16, 21- 
22, and 23-00 hours. From 0 am to 4 am, there is a decline in milking activity - $10 \%$ of milking occurred.

Table 1. Ethological indicators of cows of different levels of milk productivity

\begin{tabular}{|c|c|c|c|c|c|c|}
\hline \multirow{4}{*}{ Indicator } & \multicolumn{6}{|c|}{ Group } \\
\hline & \multicolumn{2}{|c|}{$I(n=4)$} & \multicolumn{2}{|c|}{ II $(\mathrm{n}=5)$} & \multicolumn{2}{|c|}{ III $(n=6)$} \\
\hline & \multicolumn{6}{|c|}{ Daily milk yield } \\
\hline & $\mathrm{M} \pm \mathrm{m}$ & $\mathrm{Cv}, \%$ & $\mathrm{M} \pm \mathrm{m}$ & $\mathrm{Cv}, \%$ & $\mathrm{M} \pm \mathrm{m}$ & $\mathrm{Cv}, \%$ \\
\hline Daily milk yield, $\mathrm{kg}$ & $13,9 \pm 2.06$ & 29.6 & $20.5 \pm 0.78^{* *}$ & 8.5 & $26.3 \pm 0.57 * * *$ & 5.3 \\
\hline Milking number per day, times & $2.8 \pm 0.25$ & 18.2 & $3.6 \pm 0.24 *$ & 15.2 & $4.7 \pm 0.33 * *$ & 17.5 \\
\hline Time expenditure, min.: standing & $595.5 \pm 16.65$ & 5.6 & $761.0 \pm 105.30$ & 30.9 & $800.8 \pm 62.42 *$ & 19.1 \\
\hline lying & $842.5 \pm 16.65$ & 4.0 & $679.0 \pm 105.3$ & 34.7 & $639.2 \pm 62.42 *$ & 23.9 \\
\hline feed intake & $257.5 \pm 21.65$ & 16.8 & $271.0 \pm 24.46$ & 20.2 & $311.7 \pm 24.82$ & 19.5 \\
\hline \multirow{3}{*}{$\begin{array}{l}\text { chewing cud: } \\
\text { including lying down } \\
\text { including standing }\end{array}$} & $523.8 \pm 56.95$ & 21.7 & $482.5 \pm 30.45$ & 12.6 & $451.0 \pm 19.20$ & 9.5 \\
\hline & $476.7 \pm 71.90$ & 26.1 & $278.8 \pm 86.59$ & 62.1 & $251.0 \pm 53.77$ & 47.9 \\
\hline & $70.0 \pm 14.72$ & 42.1 & $175.0 \pm 56.24$ & 71.9 & $182.5 \pm 42.79$ & 57.4 \\
\hline
\end{tabular}

$*-\mathrm{p}<0,05 ; * *-\mathrm{p}<0,01$

There is a tendency to increase the time spent in the standing position with an increase in milk productivity of cows. Thus, animals of the middle productive group spent standing on average by 165.5 , of the highly productive group by 205.3 minutes more $(p<0.05)$ than animals of the low productive group.

The nutritional activity of cows has no significant differences between the groups. However, there is a tendency to increase the time for eating food in highproductivity cows - they spent 54.2 minutes more than low-productivity ones. In the chewing cud process, the opposite picture is observed: animals of the lowproduction group ruminate more-by 41.3 and 72.8 minutes than medium-and high-production animals, respectively.

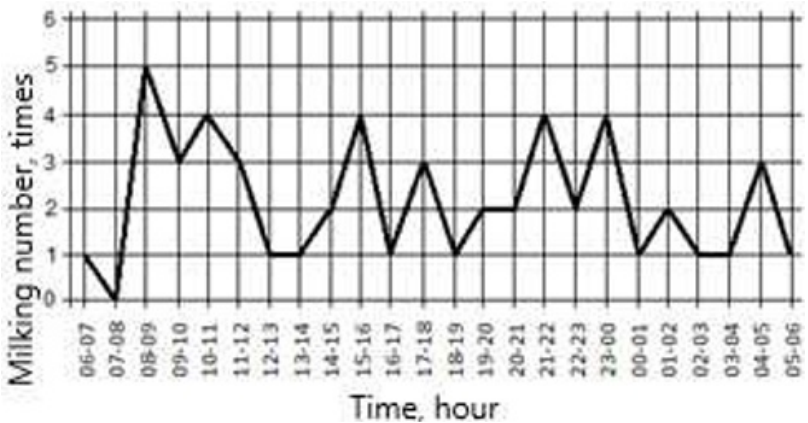

Fig. 2. Distribution of the number of milking of cows per day

At the next stage, the animals were divided into 4 groups by food, motor, and general activity: infropassive (IP), passive (P), active (A), and ultra-active (UA). In terms of nutritional activity, infropassive and passive cows were slightly more productive in terms of daily milk yield (by $1.1 \mathrm{~kg}$ ) than active and ultra-active cows (see Table 2). In general, we can conclude that the cows of this herd do not have a relationship between food activity and dairy productivity.

In terms of motor activity, active and ultra-active animals outperformed infropassive and passive peers in terms of milk productivity by $5.2 \mathrm{~kg}$, or $26.9 \%$ (p < $0.05)$. The correlation coefficient between motor activity and milk productivity also indicates a close relationship between these indicators -0.51 . Thus, the motor activity index can be considered as a selection indicator for improving the milk productivity of cows.

Active and ultra-active cows also outperform infropassive and passive cows by $2.8 \mathrm{~kg}$ in total activity, but the difference is not reliable.

Table 2. Milk productivity of cows depending on activity indices

\begin{tabular}{|c|c|c|c|}
\hline Activity class & IP+P & A+UA & Difference, \pm \\
\hline \multicolumn{4}{|c|}{ The feeding activity index } \\
\hline Number of cows & 10 & 5 & \\
\hline Index value & $0.501 \pm 0.009$ & $0.624 \pm 0.025$ & $+0.12^{* * *}$ \\
\hline Daily milk yield, kg & $21.4 \pm 1.81$ & $20.3 \pm 2.66$ & -1.1 \\
\hline \multicolumn{4}{|c|}{ The motor activity index } \\
\hline Number of cows & 10 & 5 & \\
\hline Index value & $0.433 \pm 0.017$ & $0.663 \pm 0.025$ & $+0.23^{* * *}$ \\
\hline Daily milk yield, kg & $19.3 \pm 1.88$ & $24.5 \pm 1.20$ & $+5.2^{*}$ \\
\hline \multicolumn{4}{|c|}{ The general activity index } \\
\hline Number of cows & 6 & 9 & \\
\hline Index value & $0.693 \pm 0.008$ & $0.789 \pm 0.008$ & $+0.09^{* * *}$ \\
\hline Daily milk yield, $\mathrm{kg}$ & $19.3 \pm 2.77$ & $22.1 \pm 1.58$ & +2.8 \\
\hline$*-\mathrm{p}<0,05 ; * * *-\mathrm{p}<0,001$ &
\end{tabular}

\section{Discussion}

According to our research, cows were in the lying position for an average of 706.7 minutes, or $49.1 \%$ of the daily time. The rest of the time they spent standing 733.3 minutes, or $50.1 \%$. The animals took 283.7 minutes $(19.7 \%)$ to receive the feed. The chewing cud process lasted 497.3 minutes (34.5\%), including 347.3 minutes - lying down, 150 minutes - standing.

Researchers note that cows spend 46.0-55.5\% [12], 624-682 minutes [13] of the daily time spent lying down. R. Grant [14] and K.A. Houpt [15] conclude that cows need 12 to 14 hours to rest while lying down. In general, we can note that our data are consistent with the results of other researchers. Certain differences in the duration of the behavioral acts in different studies are inevitable, which is associated with the breed, age, physiological characteristics, as well as with the conditions of management, feeding, etc.

A review of various studies shows $[4,16,17]$ that cows take from 240 to 451.8 minutes to feed, and from 
276 to 600 minutes to chew. As you can see, the indicators spread is quite significant and our results are within these values.

In our research, the following patterns were found between animal behavior and milk productivity: the higher the animal's milk productivity, the more often they are milked, the more they are in a standing position (higher motor activity index), the more they take feed and chew less cud (food activity index).

The fact that an increase in the number of milking is accompanied by increasing milking productivity is reported in many studies. Three-time milking, in comparison with two-time, increased milk yield by 3-10 \%, the transition to four - time milking-by another 5-10\% [18]. Cows milked once a day had a milk yield of $14.8 \mathrm{~kg}$, twice -23.3 , three times -27.5 , four times $31.7 \mathrm{~kg}$. The correlation coefficient between these indicators was 0.63 [19].

The activity index, as a rule, positively correlated with milk yield. In our research were found a reliable relationship between milk yield and motor activity index. Kudrin A. G. found [5] that in full-aged animals with high indices values of food, motor and general activity, the milk yield for 305 days of lactation was higher. However, first-calf cows have some differences: increased indices values of motor and general activity were characterized by lower milk yields, and food activity - large. Thus, the author concludes, these indicators are related to the age and physiological state of animals.

\section{Conclusion}

Cows in robotic milking conditions spend $50.1 \%$ of their daily time standing and $49.1 \%$ lying down. Taking a feed from animals takes $19.7 \%$ of the time, chewing cud $-34.5 \%$, of which $10.4 \%$ - standing, 24.1-lying down. Moving takes an average of $3 \%$ of the daily time.

Animals of the high-productivity group are milked 1.9 times more often than those of the low-productivity group. Milking occurs around the clock, a certain activation of the milking process is observed from 8 to 12 hours.

High-productivity cows, compared with lowproductivity cows, spend more time standing (by $34.5 \%$ ), consume more food (by $21.0 \%$ ), and chew less cud (by $13.9 \%$ ).

According to the food activity index, passive and infropassive animals were $5.4 \%$ higher than animals of the active and ultra-active groups in terms of milk productivity. According to the index of motor and general activity, the situation is the opposite in cows of the active and ultra-active groups, productivity is higher by 26.9 and $14.5 \%$, respectively.

In this herd of cows, there is a close correlation between milk productivity and motor activity index. In this regard, the cow's selection for this index will be accompanied by an increase in their milk productivity.

\section{References}

1. D. Mac-Farlend, Animal Behavior: Psychobiology, Ethology, and Evolution, Transl. from Engl. (Mir, Moscow, 1988), 520 p.

2. E.N. Panov, Etology - its origins, formation, and place in the behavior study (Moscow, 1975), $64 \mathrm{p}$.

3. V.F. Lysov, T.V. Ippolitova, V.I. Maximov et al., Physiology and ethology of animals (KolosS, Moscow, 2012), 605 p.

4. V.F. Lysov, T.E. Kostina, Ethology of farm animals (Kazan: Publ. house of KGAVM, 2003), 151 p.

5. A.G. Kudrin, S.A. Gavrilin, Ethological selection and milk productivity of cows, Agricult. biology, 4, 78-80 (2010)

6. A.F. Fraser, Ethics and Ethology, Anim. Red. Stud., 2-3, 155-163 (1980)

7. I. Akimushkin, Ethology problems (Harvest, Moscow, 1985), $193 \mathrm{p}$.

8. Z.A. Zorina, I.I. Poletaeva, Zh.I. Reznikova, Fundamentals of ethology and behavioral genetics (Publ. house "Higher school", Moscow, 2002), 384 p.

9. S.A. Gavrilin, The use of ethological indices in the selection of milk cattle and dual-purpose cattle (Cand. dissertation thesis) (Voronezh, 2009), 25 p.

10. V.I. Velikzhanin, Methodical recommendations on the use of ethological features in the milk cattle selection (VNIIGRZH, St. Petersburg, 2000), 19 p.

11. L.K. Ernst, Yu.N. Grigorievich, Efficiency improvement of stock breeding in farms of large regions (Moscow workman, Moscow, 1985), pp. $132-133$

12. A.G. Kudrin, The productivity of white-and-black cattle in connection with its behavior, Milk and meat cattle breed., 7, 33 (2002)

13. Ya. Gauptman, B. Chumlivsky, Ya. Dushek et al., Ethology of farm animals, Transl. from the Czech B.N. Pakulev, ed. by E.N. Panov (Kolos, Moscow, 1977), 304 p.

14. R. Grant, Taking advantage of natural behavior improves dairy cow performance, in: Western Dairy Manag. Conf., pp. 225-236 (NV, Reno, 2007)

15. K.A. Houpt, Domestic behaviour for veterinarians and animal scientists (Iowa State University Press, 1998), pp. 98-103. ISBN: 0-8138-1061-2

16. R.G. Dado, M.S. Allen, Variation in and relationships among feeding, chewing, and drinking variables for lactating dairy cows, J. Dairy Sci., 85, 132-144 (1994)

17. B.J., Tolkamp, D.P.N. Schweitzer, I. Kyriazakis, The biologically relevant unit for the analysis of short-term feeding behavior of dairy cows, J. Dairy Sci., 83, 57-68 (2000) 
18. J. Hamann, F.H. Dodd, Milking Routines, In: Machine milking and lactation (Insight Books, Berkshire, Vermont, 1992), pp. 69-96
19. R.R. Khisamov, N.A. Safiullin, L.R. Zagidullin, Reaction of first-calf cows to the voluntary milking system, Milk and meat cattle breed., 3, 23-25 (2016) 